\title{
pro.posições

ARTIGOS

\section{Implementação da Lei 10.639/2003 - competências, habilidades e pesquisas para a transformação social}

\section{Implementation of Law 10.639/2003 - skills, abilities and research for social change}

Marco Antonio Bettine de Almeida ${ }^{i}$ Livia Pizauro Sanchez ii iii

i Professor Dr. Associado, Escola de Artes, Ciências e Humanidades, Universidade de São Paulo, SP, Brasil. marcobettine@gmail.com

ii Escola de Artes, Ciências e Humanidades, Universidade de São Paulo, SP, Brasil. livia.pizauro@usp.br

iii Assembleia Legislativa do Estado de São Paulo, SP, Brasil.

\begin{abstract}
Resumo
A Lei 10.639/2003 institui a obrigatoriedade do ensino de História e Cultura Africana e Afro-Brasileira nos currículos da Educação Básica no Brasil. Este estudo busca compreender as razões da dificuldade de sua implementação, por meio da análise das políticas públicas federais e das produções acadêmicas a ela relacionadas, durante seus primeiros dez anos de vigência. Concluiu-se que a coesão entre as diversas políticas educacionais é fator, entre outros, que corrobora a efetivação dessa legislação. Os problemas encontrados na execução da Lei 10.639/03 estão inseridos nas dificuldades estruturais do sistema educacional brasileiro e em suas bases ideológicas racistas.

Palavras-chave: Lei 10.639/2003, políticas públicas, legislação, implementação, produção acadêmica
\end{abstract}




\section{pro-posições}

\section{Abstract}

The Law 10.639/2003 establishing the compulsory teaching of History and Culture and African Afro-Braqilian in the curricula of basic education in Braqil. This study aims to understand the reasons for the difficulty of its implementation, through analysis of federal public policy and academic productions related to it during its first ten years of operation. We concluded that the cohesion between the various educational policies is a factor, among others, which confirms the effectiveness of this legislation. The problems found in the execution of Law 10.639/03 are into the structural difficulties of Brazilian educational system and its racist ideological bases.

Keywords: Law 10.639/2003, public policy, legislation, implementation, academic production

\section{Introdução}

Os embates históricos que tentaram explicitar as finalidades da educação formal intencional, sistemática e realizada no espaço escolar (Santos, 2001) - trazem duas abordagens principais: ora ela foi percebida como meio para a transformação social, ora como forma de reprodução das estruturas de poder. Conforme Gadotti (2008), essas percepções surgem de forma descontínua: os movimentos da prática e do pensamento pedagógicos não se dão como um progresso linear, em que ideias antigas são superadas e substituídas pelas novas.

Por ser reconhecida como forma estratégica de intervenção na realidade, a Educação tornou-se cenário de disputas políticas e ideológicas, sendo um dos principais campos a elaboração de leis. Leis são frutos de processos de embates e disputas de grupos organizados da sociedade em torno de múltiplos interesses. Sua aprovação significa, ao mesmo tempo, o ápice desses processos - já que declarar algo como direito é reconhecê-lo politicamente (Gentili, 2009) - e a continuidade do percurso de busca por sua realização, problematização e revisão no cotidiano das instituições e das relações humanas. 


\section{pro.posıções}

eISSN 1980-6248

Aprovada em 9 de janeiro de 2003, a Lei 10.639/2003 faz alterações à Lei de Diretrizes e Bases da Educação Nacional para implantar a obrigatoriedade do ensino de História e Cultura Afro-Brasileira nas escolas públicas e privadas de Ensino Fundamental e Médio e estabelecer especificações pertinentes.

Essa aprovação, fruto de longa história de lutas pelo reconhecimento e pela reparação das desigualdades entre populações brancas e negras no Brasil, é vista como marco do avanço no tratamento da questão do ponto de vista governamental e legal, já que “declarar direitos é um recurso político-pedagógico que expressa um modo de conceber as relações sociais dentro de um país" (Cury, 2000, p.32).

Entendemos a Lei 10.639/2003, primeiramente, como uma política de ação afirmativa, pois:

Os objetivos das ações afirmativas são: induzir transformações de ordem cultural, pedagógica e psicológica, visando a tirar do imaginário coletivo a idéia de supremacia racial versus subordinação racial e/ou de gênero; coibir a discriminação do presente; eliminar os efeitos persistentes (psicológicos, culturais e comportamentais) da discriminação do passado, que tendem a se perpetuar e que se revelam na discriminação estrutural; implantar a diversidade e ampliar a representatividade dos grupos minoritários nos diversos setores . (Gomes, 2001)

A Lei 10.639/2003 questiona o currículo oficial. É por meio dele que se escolhem as prioridades do que ensinar ou não na escola e, por isso, houve uma naturalização de seus conteúdos como uma representação da verdade. O currículo é âmbito de construção política de representações oficialmente aceitas - de mundo, de sociedade, de pessoas -, das quais se entende que todo cidadão deva apropriar-se, dada a obrigatoriedade de frequência à Educação Básica no Brasil. Assim, a Lei 10.639/03 tem o potencial de permitir aos alunos negros o reconhecimento e a valorização, subjetivos e simbólicos, de sua identidade e de sua importância na formação da sociedade brasileira. A legislação representa um avanço na democratização do currículo: "É tarefa da escola fazer com que a História seja contada a mais vozes, para que o futuro seja escrito a mais mãos" (Santos, 2001, p.20). A escola é um espaço privilegiado para essa tarefa, já que é "sistemática, constante e obrigatória" (Figueira, 1999, p. 21). 


\section{pro.posıções}

eISSN 1980-6248

A Lei 10.639/03 tem, assim, caráter compensatório, ao possibilitar a desconstrução de mentalidades e práticas preconceituosas, sequelas deixadas pelo longo período de escravização, visto que "as desigualdades raciais ou de gênero, como quaisquer outras, não se inscrevem na lógica da natureza, mas na lógica das relações. [...] São socialmente criados; podem e devem ser politicamente dirimidos" (Siss, 2003, p.34).

Por outro lado, a lei não garante, por si só, a efetivação de seus preceitos. Ela se torna mais um instrumento para que, na dinâmica sociopolítica e no próprio cotidiano escolar, com todas as contradições, conflitos e embates que ali se dão, sejam produzidos os significados e os valores em torno de seu conteúdo. Não há uma relação direta e imediata entre o ensino da história e da cultura afro-brasileira e a mudança das relações sociais desiguais, mas ele pode ser instrumento de tensionamento das desigualdades raciais, caminho para a desconstrução gradual de mentalidades e práticas sociais discriminatórias, por meio da tentativa de estabelecer diálogos entre visões, concepções e experiências múltiplas - sem que se preestabeleçam a superioridade e a dominação de umas sobre as demais (Cerri, 2006) - e da construção coletiva de uma realidade que contemple a diversidade, garantindo que alguns grupos não apenas deixem de ser responsabilizados por não se adequarem a espaços que os discriminam, mas também saiam do seu local de invisibilidade, silenciamento, exclusão.

Pressupomos que uma educação direcionada por esses preceitos poderá produzir reflexos nas relações sociais vividas por indivíduos formados a partir de novos olhares e posturas diante do conhecimento e da apropriação de valores e atitudes pautados na igualdade de direitos e no respeito às diferenças, capacitados para intervir no mundo e transformá-lo.

O presente artigo é o resultado da busca, constatada em experiências empíricas e em pesquisas (Fernandes, 2005; Santos, 2005; Silva, 2007), por investigar e compreender as dificuldades do processo de implementação dessa legislação.

Para identificar obstáculos à implantação dessa lei, trazemos dois levantamentos: o primeiro, de políticas públicas realizadas com o objetivo de subsidiar a implementação da Lei 10.639/2003 durante sua primeira década de existência, e o outro, das produções acadêmicas do mesmo período que tratavam a respeito da legislação. 


\section{pro.posıções}

e-ISSN 1980-6248

Identificamos, na análise desses levantamentos, diversas dificuldades no processo de implantação da Lei 10.639/2003, relacionadas à formação de profissionais de ensino, à disponibilidade e à divulgação de recursos para o ensino, à intolerância religiosa, entre outros. Esses fatores indicam pouca preocupação em estabelecer vínculos entre políticas públicas relacionadas a essa lei (incluídas a própria lei e suas regulamentações posteriores) e entre elas e as demais políticas educacionais, o que garantiria certo grau de coesão entre as políticas, favorecendo a implementação de todas elas. Consideramos, ainda, que o cerne dos problemas enfrentados na execução da Lei 10.639/03 encontra-se na sua inserção em um sistema educacional com bases ideológicas racistas.

\section{Levantamento das Políticas Públicas}

Apresentamos um levantamento de políticas públicas federais voltadas à implementação da Lei 10.639/2003 durante os dez primeiros anos de sua vigência, com a intenção de evidenciar seus focos e traçar um quadro geral que possibilite a observação e a discussão de suas ênfases e lacunas.

Muitas ações nesse sentido têm sido encabeçadas por entidades internacionais ligadas ao combate ao racismo, organizações não governamentais, grupos do Movimento Negro, associações culturais e pela atuação de gestores e professores interessados no assunto, muitas vezes sem apoio institucional e com recursos pessoais (Celani, 2008). São iniciativas importantes para a garantia da efetivação dessa lei. O foco do presente artigo, porém, encontra-se nas iniciativas governamentais, sem ignorar tais ações.

Secchi (2012) afirma que uma política pública é uma diretriz elaborada para enfrentar um problema público. Uma política é pública, quando o problema que a motiva é relevante para a coletividade e enfrentado por uma pluralidade de atores públicos, entre os quais o Estado, os partidos políticos, a sociedade civil organizada e os movimentos sociais; todos esses atores têm papel central, já que existem com a finalidade de elaborar políticas públicas para a transformação da sociedade. Apesar de o Estado deter o monopólio do uso da força e controlar boa parte das ações sociais, hoje é impossível construir políticas sem a interface com a pluralidade de sujeitos e grupos organizados, o que permite executar iniciativas mais estruturais, mais estratégicas e de maior alcance. 


\section{pro.posıções}

eISSN 1980-6248

A análise histórica do cenário brasileiro e das políticas e práticas relacionadas à educação no Brasil, a partir de um enfoque interdisciplinar, possibilita a reconstrução crítica do passado e a formação de uma consciência política para a melhor compreensão do presente. Diante da rápida e intensa transformação sofrida pelo Brasil nas últimas décadas, nosso trabalho neste artigo tentará contribuir com as ações políticas recentes e a ação de diferentes forças para a situação atual da Lei 10.639/2003, com foco nas competências, nas habilidades e nas pesquisas para a transformação social.

Optamos pela apresentação de ações dos órgãos dos Poderes Legislativo e Executivo, em âmbito federal ${ }^{1}$.

Os dados obtidos foram organizados em quatro eixos temáticos: Regulamentação, Formação, Material e Articulação ${ }^{2}$, que apresentamos a seguir.

\section{Eixo 1: Regulamentação}

Neste eixo estão incluídas nove políticas que regulamentam a Lei 10.639/2003, sendo quatro relacionadas à criação de órgãos para atuação na área da igualdade racial, dos quais dois têm a função de realizar intervenções especificamente no campo educacional. Três leis contemplam os conteúdos da Lei 10.639/2003 e três documentos explicam e justificam essa mesma lei, indicando os caminhos para sua implementação, conforme o Quadro 1.

\footnotetext{
${ }^{1}$ Detalhamento e justificativas dos critérios de pesquisa utilizados para realização do levantamento constam em Sanchez (2014).

2 A política de fortalecimento dos núcleos de estudos afro-brasileiros está localizada em mais de um eixo, pois foi instrumento estratégico de articulação e transversalidade em relação às diversas políticas públicas voltadas à Lei 10.639/2003. Por meio do incentivo e da pressão gerados pela atuação dos núcleos nas instituições de ensino superior, a partir do ano de 2004, muitas delas começaram a incluir a disciplina História da África nos cursos de graduação em História e outras disciplinas relativas à Lei 10.639/2003, em cursos de graduação. A partir de 2009, iniciaram-se os concursos específicos para contratação de professores de História da África e, em 2012, a lei tornou-se um dos itens de avaliação dos cursos superiores. Todas essas ações geraram impacto positivo no crescimento do número das pesquisas e atividades de ensino e extensão relacionadas à temática (Prado \& Graf, 2010).
} 


\title{
pro.posıções
}

eISSN 1980-6248

\author{
Quadro 1 - Políticas Públicas de implementação da Lei 10.639/2003 - Eixo \\ Regulamentação
}

\begin{tabular}{|c|c|c|}
\hline POLÍTICA & OBJETIVOS & AÇÕES \\
\hline $\begin{array}{l}\text { Criação da Secretaria de } \\
\text { Políticas de Promoção da } \\
\text { Igualdade Racial }\end{array}$ & $\begin{array}{l}\text { Formular, coordenar e } \\
\text { articular políticas, diretrizes, } \\
\text { programas } \\
\text { Implementar legislações } \\
\text { para promoção da } \\
\text { igualdade racial. }\end{array}$ & \\
\hline $\begin{array}{l}\text { Criação da } \\
\text { Educação } \\
\text { Alfabetização } \\
\text { Diversidade }\end{array}$ & $\begin{array}{l}\text { Efetivar Políticas Públicas de } \\
\text { valorização da diversidade. }\end{array}$ & \\
\hline Parecer 003/2004 & $\begin{array}{l}\text { Orientar a implementação } \\
\text { da Lei } 10.639 / 2003 \text {. }\end{array}$ & $\begin{array}{l}\text { Atribuição de competências; determinação de } \\
\text { estratégias para formação; inclusão da Educação } \\
\text { Infantil, do Ensino Superior e de instituições de } \\
\text { formação inicial e continuada na responsabilidade } \\
\text { pela implementação da Lei; incentivo à produção e } \\
\text { à divulgação de livros, materiais didáticos e } \\
\text { experiências pedagógicas; destaque à importância } \\
\text { do Movimento Negro e dos Núcleos de Estudos } \\
\text { Afro-Brasileiros }\end{array}$ \\
\hline $\begin{array}{l}\text { Diretrizes Curriculares } \\
\text { Nacionais para a Educação } \\
\text { das Relações Étnico- } \\
\text { raciais e para o Ensino de } \\
\text { História e Cultura Afro- } \\
\text { Brasileira e Africana } \\
\text { (Resolução 001/04) }\end{array}$ & $\begin{array}{l}\text { Orientar a implementação } \\
\text { da Lei } 10.639 / 2003 \text {. }\end{array}$ & Distribuição de exemplares para professores(as) \\
\hline $\begin{array}{l}\text { Fórum } \\
\text { Intergovernamental de } \\
\text { Promoção da Igualdade } \\
\text { Racial }\end{array}$ & $\begin{array}{l}\text { Estimular a implementação } \\
\text { da Política Nacional de } \\
\text { Promoção da Igualdade } \\
\text { Racial. }\end{array}$ & $\begin{array}{l}\text { Filiação de } 669 \text { municípios } \\
\text { Assistência financeira para formação de } \\
\text { professores e aquisição de material didático no } \\
\text { Ensino Fundamental, nas capitais da Federação, no } \\
\text { Distrito Federal e nos municípios filiados ao Fórum }\end{array}$ \\
\hline $\begin{array}{lr}\text { Comissão } & \text { Técnica } \\
\text { Nacional de } & \text { Diversidade } \\
\text { para } & \text { assuntos } \\
\text { relacionados à educação } \\
\text { dos afro-brasileiros }\end{array}$ & $\begin{array}{l}\text { Elaborar, acompanhar, } \\
\text { analisar e avaliar Políticas } \\
\text { Públicas relacionadas à Lei } \\
\text { 10.639/2003. }\end{array}$ & \\
\hline $\begin{array}{l}\text { Política Nacional de } \\
\text { Formação de Profissionais } \\
\text { do Magistério da } \\
\text { Educação Básica }\end{array}$ & $\begin{array}{l}\text { Organizar a formação inicial } \\
\text { e continuada. }\end{array}$ & $\begin{array}{l}\text { Questões relacionadas à Lei } 10.639 / 2003 \text { e suas } \\
\text { regulamentações }\end{array}$ \\
\hline $\begin{array}{l}\text { Plano Nacional de } \\
\text { Implementação das } \\
\text { Diretrizes Curriculares } \\
\text { Nacionais da Educação } \\
\text { das Relações Étnico- } \\
\text { Raciais e para o Ensino de } \\
\text { História e Cultura Afro- } \\
\text { Brasileira e Africana }\end{array}$ & $\begin{array}{l}\text { Fortalecer e institucionalizar } \\
\text { as orientações que já } \\
\text { existiam. }\end{array}$ & $\begin{array}{l}\text { Estabelecimento de metas e estratégias para a } \\
\text { execução da Lei 10.639/2003; delimitação de } \\
\text { responsabilidades dos atores governamentais; } \\
\text { proposição de ações de formação de professores; } \\
\text { sensibilização de gestores; e produção de material } \\
\text { didático }\end{array}$ \\
\hline
\end{tabular}




\section{pro.posıções \\ eISSN 1980-6248}

\begin{tabular}{|c|c|c|}
\hline $\begin{array}{l}\text { Estatuto da Igualdade } \\
\text { Racial }\end{array}$ & $\begin{array}{l}\text { Proteger os direitos da } \\
\text { população negra. }\end{array}$ & $\begin{array}{l}\text { Reafirmação da obrigatoriedade do estudo da } \\
\text { História Geral da África e da História da população } \\
\text { negra no Brasil } \\
\text { Determinação de que o Poder Executivo fomente a } \\
\text { formação inicial e continuada dos professores e a } \\
\text { elaboração de material didático específico } \\
\text { Incentivo à formação de grupos, núcleos e centros } \\
\text { de pesquisa nos programas de Pós-Graduação e à } \\
\text { inclusão de temas relativos à pluralidade étnica e } \\
\text { cultural nos currículos dos cursos de formação de } \\
\text { professores }\end{array}$ \\
\hline
\end{tabular}

Todos os documentos possuem enfoque semelhante, considerando a Lei 10.639/03 como uma forma de reparação de uma dívida social com a população negra, contraída em função do longo período escravista, das políticas de embranquecimento, do mito da democracia racial e das práticas racistas. As ações sociais decorrentes da implementação da legislação permitiriam reconhecer e valorizar a história, a cultura e a identidade dos negros. Essa implantação atingiria de forma positiva todo o contingente escolar, ao exigir instituições educacionais em boas condições materiais e professores com formação de qualidade. Também defendem a ideia de que não basta incluir conteúdos programáticos no currículo, pois a Lei somente pode ser aplicada se forem repensadas as relações dentro e fora da escola, os "procedimentos de ensino, condições oferecidas para a aprendizagem, objetivos tácitos e explícitos da educação oferecida pelas escolas" (Silva \& Araújo, 2005, p.15).

\section{Eixo 2: Formação}

Neste eixo foram contempladas as políticas ligadas à promoção de formação de professores e profissionais do ensino, conforme indicado no Quadro 2. 


\section{pro.posıções \\ eISSN 1980-6248}

Quadro 2 - Políticas Públicas de implementação da Lei 10.639/2003 - Eixo Formação

\begin{tabular}{|c|c|c|}
\hline POLÍTICA & OBJETIVOS & AÇÕES \\
\hline $\begin{array}{l}\text { Fortalecimento dos Núcleos de } \\
\text { Estudos Afro-Brasileiros }\end{array}$ & $\begin{array}{l}\text { Avaliar, acompanhar e incentivar a } \\
\text { execução das Diretrizes Curriculares } \\
\text { Nacionais. }\end{array}$ & $\begin{array}{l}\text { Pesquisa, divulgação de } \\
\text { conhecimentos, coleta de } \\
\text { informações, produção e } \\
\text { avaliação de materiais didático- } \\
\text { pedagógicos }\end{array}$ \\
\hline $\begin{array}{l}\text { Programa de Ações Afirmativas } \\
\text { para a População Negra nas } \\
\text { Instituições Federais e } \\
\text { Estaduais de Educação Superior }\end{array}$ & $\begin{array}{l}\text { Ampliar a inserção da temática } \\
\text { étnico-racial no Ensino Superior. }\end{array}$ & $\begin{array}{l}\text { Suporte técnico e financeiro a } \\
\text { núcleos de estudos afro- } \\
\text { brasileiros; publicação e } \\
\text { distribuição de livros; formação } \\
\text { de professores }\end{array}$ \\
\hline $\begin{array}{l}\text { Projeto “Geografia Afro- } \\
\text { Brasileira - Educação e } \\
\text { Planejamento do Território" }\end{array}$ & $\begin{array}{l}\text { Oferecer instrumentos para } \\
\text { compreender matrizes geográficas } \\
\text { da África presentes no Brasil e a } \\
\text { formação dos quilombos. }\end{array}$ & $\begin{array}{l}\text { Oficina temática em sete } \\
\text { capitais }\end{array}$ \\
\hline $\begin{array}{l}\text { Projeto piloto do curso Gênero } \\
\text { e Diversidade na Escola }\end{array}$ & Formar professores. & $\begin{array}{l}\text { Formação de educadores a } \\
\text { distância }\end{array}$ \\
\hline $\begin{array}{l}\text { Sistema Universidade Aberta } \\
\text { do Brasil }\end{array}$ & $\begin{array}{l}\text { Articular as universidades públicas } \\
\text { para o oferecimento de cursos a } \\
\text { distância. }\end{array}$ & $\begin{array}{l}\text { Curso Gestão de Políticas } \\
\text { Públicas em Gênero e Raça }\end{array}$ \\
\hline $\begin{array}{l}\text { Formação de professores em } \\
\text { História da Cultura Afro- } \\
\text { Brasileira e Africana }\end{array}$ & Capacitar professores. & $\begin{array}{l}\text { Curso relativo à temática da } \\
\text { história e cultura afro-brasileira } \\
\text { e africana, na modalidade a } \\
\text { distância }\end{array}$ \\
\hline $\begin{array}{l}\text { Programa "Educação- } \\
\text { Africanidades-Brasil" }\end{array}$ & Oferecer formação continuada. & Compartilhamento de textos \\
\hline $\begin{array}{l}\text { Universidade da Integração } \\
\text { Internacional da Lusofonia } \\
\text { Afro-Brasileira }\end{array}$ & $\begin{array}{l}\text { Implementar atividades acadêmicas } \\
\text { para compreensão e superação dos } \\
\text { temas e dos problemas comuns aos } \\
\text { países parceiros. }\end{array}$ & Cinco cursos de especialização \\
\hline
\end{tabular}

Além das atividades dos núcleos de estudos afro-brasileiros, outras sete políticas foram identificadas, voltadas para a formação continuada de professores. Duas englobaram outros profissionais da Educação: um curso para gestores e uma especialização para quaisquer profissionais do ensino. 


\section{pro.posıções}

Poucas dessas políticas contemplam atividades de compartilhamento do saber adquirido e socializado durante as formações, o que garantiria sua maior expansão. Publicações, exposições, formação continuada em serviço e a atuação dos formandos como multiplicadores são modalidades presentes; porém, não há preocupação explícita com o controle e a abrangência dessas formas de disseminação de saberes, nem se preveem a exigência e o acompanhamento das ações práticas decorrentes dos cursos realizados.

\section{Eixo 3: Material}

Neste eixo localizamos as Políticas Públicas para produção e distribuição de materiais didáticos para alunos e de materiais de apoio para o professor.

Foram identificadas sete políticas, descritas no Quadro 3. Quatro delas se preocupam com a disseminação de materiais voltados exclusivamente para professores, uma com materiais para uso dos alunos e duas, para ambos. Quadro 3 - Políticas Públicas de implementação da Lei 10.639/2003 - Eixo
Material

\begin{tabular}{l|l|l}
\hline POLÍTICA & OBJETIVOS & \multicolumn{2}{l}{ AÇÕES } \\
\hline $\begin{array}{l}\text { Fortalecimento dos } \\
\text { núcleos de estudos } \\
\text { afro-brasileiros }\end{array}$ & $\begin{array}{l}\text { Avaliar, acompanhar e } \\
\text { incentivar a execução das } \\
\text { Diretrizes Curriculares } \\
\text { Nacionais. }\end{array}$ & $\begin{array}{l}\text { Pesquisa, divulgação de conhecimentos, coleta de } \\
\text { informações, produção e avaliação de materiais } \\
\text { didático-pedagógicos }\end{array}$ \\
\hline $\begin{array}{l}\text { Projeto “A cor da } \\
\text { cultura” }\end{array}$ & $\begin{array}{l}\text { Implementar ações } \\
\text { culturais e ferramentas } \\
\text { audiovisuais. }\end{array}$ & Programas para televisão, kit “A cor da cultura” \\
\hline $\begin{array}{l}\text { Distribuição de } \\
\text { livros para } \\
\text { professores }\end{array}$ & $\begin{array}{l}\text { Fortalecer o conhecimento } \\
\text { dos profissionais da } \\
\text { Educação. }\end{array}$ & Publicação e distribuição de livros \\
\hline
\end{tabular}




\section{pro.posições}

eISSN 1980-6248

\begin{tabular}{|c|c|c|}
\hline $\begin{array}{l}\text { Programa Nacional } \\
\text { do Livro Didático }\end{array}$ & $\begin{array}{l}\text { Incluir as questões } \\
\text { relacionadas à Lei } \\
10.639 / 2003 \text { como uma } \\
\text { das exigências técnicas } \\
\text { para escolha dos livros. }\end{array}$ & $\begin{array}{l}\text { Exigência de que, nos livros de todas as disciplinas, } \\
\text { sejam abordadas as questões de relações etnorraciais } \\
\text { e denunciadas as formas de violência nesse sentido; } \\
\text { haja estímulo a ações afirmativas em relação a etnias } \\
\text { e à promoção de uma sociedade antirracista; sejam } \\
\text { trabalhadas essas temáticas continuamente; não se } \\
\text { veiculem estereótipos étnico-raciais. }\end{array}$ \\
\hline $\begin{array}{l}\text { Coleção História } \\
\text { Geral da África }\end{array}$ & $\begin{array}{l}\text { Disponibilizar o material } \\
\text { para acesso dos } \\
\text { professores }\end{array}$ & Atualização e tradução da coleção \\
\hline Kits de apoio & $\begin{array}{l}\text { Apoiar o trabalho dos } \\
\text { educadores com os } \\
\text { conteúdos da Lei. }\end{array}$ & Distribuição de kits \\
\hline $\begin{array}{l}\text { Programa Nacional } \\
\text { Biblioteca na } \\
\text { Escola }\end{array}$ & $\begin{array}{l}\text { Prover as bibliotecas } \\
\text { escolares. }\end{array}$ & Previsão de aquisição de livros temáticos \\
\hline
\end{tabular}

A predominância da produção de materiais para apoio ao docente é adequada, pois é desejável que ele produza, a partir de seus conhecimentos e experiências, e das realidades e coletivos humanos com que interage, as melhores alternativas didáticas e metodológicas para sua intervenção. "A prática reflexiva quer compreender para regular, otimizar, ordenar, fazer evoluir uma prática particular a partir do seu interior" (Perrenoud, 1999, p.12). Para isso, o docente precisa ter disponíveis informações e fontes de pesquisa adequadas e acessíveis.

A existência de materiais direcionados ao alunado também é positiva, mas é fundamental integrar os conhecimentos pertinentes a essa lei a todos os recursos didáticos utilizados pelos estudantes.

O pensamento contextual busca sempre a relação de inseparabilidade e as inter-retroações entre qualquer fenômeno e seu contexto, e deste com o contexto planetário. O complexo requer um pensamento que capte relações, inter-relações, implicações mútuas, fenômenos multidimensionais, realidades que são simultaneamente solidárias e conflitivas ... que respeite a diversidade, um pensamento organizador que conceba a relação recíproca entre todas as partes. (Morin, 2005) 


\section{pro.posıções \\ eISSN 1980-6248}

\section{Eixo 4: Articulação}

No Eixo Articulação, conforme o Quadro 4, localizamos as políticas que promoveram espaços de troca de conhecimentos, de experiências e de construção coletiva de estratégias para a implementação da Lei 10.639/2003.

\section{Quadro 4 - Políticas Públicas de implementação da Lei 10.639/2003 - Eixo Articulação}

\begin{tabular}{|c|c|c|}
\hline POLÍTICA & OBJETIVOS & AÇÕES \\
\hline $\begin{array}{l}\text { Fortalecimento dos } \\
\text { núcleos de estudos } \\
\text { afro-brasileiros }\end{array}$ & $\begin{array}{l}\text { Avaliar, acompanhar e } \\
\text { incentivar a execução das } \\
\text { Diretrizes Curriculares } \\
\text { Nacionais. }\end{array}$ & $\begin{array}{l}\text { Pesquisa, divulgação de conhecimentos, coleta } \\
\text { de informações, produção e avaliação de } \\
\text { materiais didático-pedagógicos }\end{array}$ \\
\hline $\begin{array}{l}\text { Reuniões de } \\
\text { articulação }\end{array}$ & Articular órgãos. & Reuniões, criação de Fóruns \\
\hline Fóruns estaduais & $\begin{array}{l}\text { Fazer o controle social da } \\
\text { implementação da Lei. }\end{array}$ & $\begin{array}{l}\text { Ampliação do número de Fóruns } \\
\text { Monitoramento de atividades da implementação } \\
\text { Reuniões e atividades de articulação }\end{array}$ \\
\hline $\begin{array}{l}\text { Conferência } \\
\text { Nacional de } \\
\text { Promoção da } \\
\text { Igualdade Racial - } \\
\text { Estado e Sociedade } \\
\text { Promovendo a } \\
\text { Igualdade Racial }\end{array}$ & $\begin{array}{l}\text { Construir coletivamente } \\
\text { propostas para um Plano } \\
\text { Nacional de Promoção da } \\
\text { Igualdade Racial. }\end{array}$ & $\begin{array}{l}\text { Sete propostas: assegurar a implementação das } \\
\text { Diretrizes Curriculares; implementar ações de } \\
\text { planejamento; elaborar e avaliar de projetos } \\
\text { político-pedagógicos; estimular iniciativas de } \\
\text { formação de professores no Ensino Superior; } \\
\text { criar sites de apoio ao Ministério da Educação } \\
\text { para troca de experiências desenvolvidas; } \\
\text { divulgar a Lei na mídia; garantir a fiscalização do } \\
\text { seu cumprimento. }\end{array}$ \\
\hline $\begin{array}{l}\text { Conferência } \\
\text { Nacional de } \\
\text { Educação Básica }\end{array}$ & $\begin{array}{l}\text { Refletir coletivamente sobre } \\
\text { a construção de práticas de } \\
\text { melhoria da qualidade da } \\
\text { Educação Básica. }\end{array}$ & $\begin{array}{l}\text { Eixos temáticos Inclusão e Diversidade na } \\
\text { Educação Básica }\end{array}$ \\
\hline Diálogos Regionais & $\begin{array}{l}\text { Discutir avanços e problemas } \\
\text { na implementação da Lei } \\
10.639 / 2003 \text {. }\end{array}$ & $\begin{array}{l}\text { Encontros; revisão coletiva do Documento } \\
\text { Referência }\end{array}$ \\
\hline $\begin{array}{l}\text { Grupo de Trabalho } \\
\text { Interministerial }\end{array}$ & $\begin{array}{l}\text { Elaborar Plano Nacional para } \\
\text { implementação e } \\
\text { acompanhamento da Lei }\end{array}$ & Elaboração e promulgação do Plano \\
\hline
\end{tabular}




\section{pro.posıções \\ eISSN 1980-6248}

\begin{tabular}{l|l|l}
\hline & $10.639 / 2003$. & \\
\hline $\begin{array}{l}\text { Conferência } \\
\text { Nacional de } \\
\text { Educação }\end{array}$ & $\begin{array}{l}\text { Construir o novo Plano } \\
\text { Nacional de Educação, para } \\
\text { vigência entre 2011 e 2020. }\end{array}$ & $\begin{array}{l}\text { Projeto de Lei número 8.035/2010, que } \\
\text { implantaria o Plano no decênio citado }\end{array}$ \\
\hline
\end{tabular}

Essas oportunidades de articulação contemplam múltiplas representações dos entes públicos e da sociedade civil.

\section{Levantamento bibliográfico}

Apresentamos, no Quadro 5, um levantamento de publicações sobre a Lei 10.639/03. A pesquisa foi feita na Biblioteca Digital Brasileira de Teses e Dissertações, com buscas livres. $^{3}$

Foram encontrados quarenta e quatro trabalhos. A abordagem mais recorrente foram os estudos de caso, que buscavam compreender o papel e a atuação do professor e das escolas na implementação da Lei. Em seguida, foram encontradas produções que investigaram a utilização de recursos para o ensino (dança popular, jogos, literatura, museus virtuais e sites de comunidades quilombolas). Seis estudos refletiram sobre a África na formação da cultura brasileira, um abordou o racismo. Quatro trabalhos investigaram a formação continuada de professores e outros cinco, os livros didáticos. Três produções referiram-se à formação inicial de professores no Ensino Superior e quatro analisaram políticas públicas de implementação da legislação. Duas delas apontam para a desarticulação entre políticas com campo étnico-racial.

\footnotetext{
${ }^{3}$ Detalhamento e justificativas dos critérios de pesquisa utilizados para realização do levantamento constam em Sanchez (2014). As buscas foram feitas entre os dias 7 e 8 de março de 2013 (referentes ao período de janeiro de 2003 a janeiro de 2013) e entre os dias 6 e 7 de fevereiro de 2016 (referentes ao período de fevereiro a dezembro de 2013), com a finalidade de contemplar todo o ano de comemoração do primeiro decênio de existência da Lei 10.639/2003.
} 


\section{pro.posıções \\ e-ISSN 1980-6248}

As áreas do saber presentes nas pesquisas foram História, Artes, Língua Portuguesa, Educação Física, Geografia, Inglês e Química. Duas delas estudaram a modalidade de Educação de Jovens e Adultos, uma investigou a Educação a distância e três se debruçaram sobre a Educação não formal ou interdisciplinar. Três produções avaliaram a Educação quilombola.

\section{Quadro 5 - Levantamento bibliográfico - Biblioteca Digital Brasileira de Teses e} Dissertações - 2003 a 2013 - Lei 10.639/2003

\begin{tabular}{|c|c|}
\hline TÍTULO & FOCO \\
\hline $\begin{array}{l}\text { O Reisado em Juazeiro do Norte e os conteúdos de } \\
\text { História e Cultura Africana e Afrodescendente: } \\
\text { uma proposta para a implementação da Lei } \\
\text { 10.639/03 }\end{array}$ & $\begin{array}{l}\text { Reisado como possibilidade de promover o } \\
\text { aprendizado da cultura afro-brasileira }\end{array}$ \\
\hline $\begin{array}{l}\text { Educação continuada e o ensino de História e } \\
\text { Cultura Afro-Brasileira e Africana: um estudo sobre } \\
\text { o Programa São Paulo: educando pela diferença } \\
\text { para a igualdade }\end{array}$ & $\begin{array}{l}\text { Proposta do Programa São Paulo: Educando pela } \\
\text { Diferença para a Igualdade }\end{array}$ \\
\hline $\begin{array}{l}\text { A África no curso de licenciatura em História da } \\
\text { Universidade Federal do Rio Grande do Sul: } \\
\text { possibilidades de efetivação da Lei 11.645/2008 e } \\
\text { da Lei 10.639/2003: um estudo de caso }\end{array}$ & $\begin{array}{l}\text { Problematização da formação do professor de História } \\
\text { na área de História da África na UFRS }\end{array}$ \\
\hline $\begin{array}{l}\text { O ensino da História e Cultura Afro-Brasileira na } \\
\text { óptica do coordenador pedagógico }\end{array}$ & $\begin{array}{l}\text { Compreensão do coordenador sobre o ensino de } \\
\text { História e Cultura Afro-Brasileira }\end{array}$ \\
\hline $\begin{array}{l}\text { Jogos africanos e afro-brasileiros nas aulas de } \\
\text { Educação Física: processos educativos das relações } \\
\text { étnico-raciais }\end{array}$ & $\begin{array}{l}\text { Uso de jogos de origem ou descendência africana em } \\
\text { aulas de Educação Física }\end{array}$ \\
\hline $\begin{array}{l}\text { A Lei 10.639/03 na formação de professores e o } \\
\text { pertencimento étnico-racial em escolas púbicas de } \\
\text { Porto Alegre }\end{array}$ & Estratégias de abordagem das questões raciais \\
\hline $\begin{array}{l}\text { A cor da metáfora: o racismo no livro didático de } \\
\text { Língua Portuguesa }\end{array}$ & População negra nos livros didáticos \\
\hline $\begin{array}{l}\text { Os desafios da implementação da Lei Federal n. } \\
\text { 10.639/03: entre as ações da Política Nacional de } \\
\text { Promoção da lgualdade Racial e a política } \\
\text { educacional no Maranhão }\end{array}$ & Políticas públicas educacionais do Maranhão \\
\hline $\begin{array}{l}\text { O uso de literatura de base africana e } \\
\text { afrodescendente junto a crianças de escolas } \\
\text { públicas de Fortaleza: construindo novos caminhos } \\
\text { para repensar o ser negro }\end{array}$ & Literatura africana e afrodescendente \\
\hline $\begin{array}{l}\text { Do contexto da influência ao contexto da prática: } \\
\text { caminhos percorridos para a implementação da Lei } \\
\text { n. } 10.639 / 03 \text { nas escolas municipais de Esteio - RS }\end{array}$ & $\begin{array}{l}\text { Recontextualização da Lei 10.639/03 em grupo de } \\
\text { estudos sobre africanidade }\end{array}$ \\
\hline $\begin{array}{l}\text { Lei Federal n. 10.639/03: um desafio para a } \\
\text { Educação Básica no Brasil }\end{array}$ & Prática da Lei 10.639/03 no Guarujá \\
\hline $\begin{array}{l}\text { A prática da Educação Étnico-racial: um estudo da } \\
\text { implantação da Lei Federal 10.639/03 no Paraná a }\end{array}$ & Lei 10.639/2003 no Ensino Médio em Toledo/PR \\
\hline V. 28, N.1 (82) |jan./abr. & $55-80$ \\
\hline
\end{tabular}




\section{pro.posıções \\ eISSN 1980-6248}

partir do professor como leitor do livro didático público

Personagens negros na Literatura Infanto-juvenil

no Brasil e em Moçambique (2000-2007):

entrelaçadas vozes, tecendo negritude

As relações étnico-raciais nos livros didáticos da

Educação de Jovens e Adultos: implicações

curriculares para uma sociedade multicultura

Entre a letra e o espírito: o discurso de

professores(as) sobre estudantes negros(as) pós-

implementação da Lei 10.639/03 em escola

pública

Educação e Relações Étnico-Raciais: Diálogos e

Silêncios sobre a Implementação da Lei $n$.

10639/2003 no Município de Goiânia

O estudo da História e Cultura Afro-brasileira no

Ensino Fundamental: currículos, formação e

prática docente

Museus virtuais e a formação de professores de

Artes Visuais no contexto da lei 10.639/2003

Vale do Ribeira: uma contribuição às redes virtuais

quilombolas para a formação de professores de

artes visuais na perspectiva da Lei 10.639/2003

A comunidade imaginada da afrodescendência no

contexto da "Educação das Relações Étnico-

raciais"

A bioquímica e a Lei Federal 10639/03 em espaços

formais e não formais de Educação

Quem foi Colombo? A questão étnico-racial nos

livros didáticos de História: a descrição do

colonizador após as leis 10639/03 e 11645/08

Esculpir o tempo: arte, educação e ancestralidade

entre os fons, os iorubas e os tchokwes

Relações Étnico-Raciais: orientações, leis e práticas

nas instituições de Educação Infantil

A Educação Física e as mudanças no mundo do trabalho um olhar através da aplicação do ensino da História e Cultura Afro-brasileira e africana nas escolas municipais de Bragança

Articulação entre as questões étnicas e raciais e a

Educação de pessoas jovens e adultas em

propostas pedagógicas difundidas pelo site do

Ministério da Educação

Corpo negro em Cachoeira/BA/Brasil: ritos e percursos no âmbito educativo da cidade

Feira livre de Bodocã: memória, africanidades e educação

Escola e enfrentamento do racismo: as experiências das professoras ganhadoras do prêmio "Educar para a Igualdade Racial"

"Eu sou negão, meu coração é a liberdade": diálogo sobre literatura negra ou afro-brasileira
Personagens negros nas narrativas literárias

infantojuvenis do Brasil e de Moçambique

EJA em seu caráter inter/multicultural

Impacto da Lei 10.639/03 sobre discurso e prática docentes

Curso de formação de professores sobre a História e

Cultura Africana em Goiânia

História e cultura afro-brasileira no ensino de História, nos anos finais do Ensino Fundamental

Museus virtuais na formação de professores de Artes Visuais para a Arte Afro-brasileira

Site da comunidade quilombola do Vale do Ribeira e formação continuada dos professores de Artes Visuais

Formação universitária para consolidação de comunidade da afrodescendência

Possibilidades de aplicação da Lei 10.639/03 em aulas de Química

Desdobramentos das leis nos livros didáticos de História

Arte e cultura africana

Análise de práticas pedagógicas na Educação Infantil

Aplicação da lei na Educação Física

Papel das questões étnico-raciais nas propostas do MEC para a Educação de Jovens e Adultos

Legado afrodescendente carente de visibilidade

Estudo da cultura afro-brasileira em feira livre semanal

Contribuições de práticas docentes no combate ao racismo na escola

Reflexões sobre o ensino de literatura negra ou afrobrasileira 


\section{pro.posições \\ eISSN 1980-6248}

\begin{tabular}{|c|c|}
\hline em escolas de Ensino Médio na Bahia & \\
\hline $\begin{array}{l}\text { O uso de fontes em sala de aula: a obra de Maria } \\
\text { Firmina dos Reis (1859) como mediadora no } \\
\text { estudo da escravidão negra no Brasil }\end{array}$ & Uso de fontes históricas no ensino da escravidão \\
\hline $\begin{array}{l}\text { Jongo e educação: a construção de uma identidade } \\
\text { quilombola a partir de saberes étnico-raciais do } \\
\text { corpo }\end{array}$ & Relações entre o jongo e a educação quilombola \\
\hline $\begin{array}{l}\text { O ensino da Geografia na Educação Quilombola: } \\
\text { experiência na Escola Municipal de Ensino } \\
\text { Fundamental Professora Antônia Socorro da Silva } \\
\text { Machado - Comunidade Negra Paratibe, PB }\end{array}$ & $\begin{array}{l}\text { Contribuições da Geografia para a educação } \\
\text { quilombola }\end{array}$ \\
\hline $\begin{array}{l}\text { Educação e escolarização quilombola: construções } \\
\text { político-pedagógicas em Brejo dos Crioulos, MG }\end{array}$ & Propostas curriculares em território quilombola \\
\hline $\begin{array}{l}\text { A formação para as relações étnico-raciais e a } \\
\text { profissionalização em História: saberes e práticas } \\
\text { docentes no contexto da Educação a distância }\end{array}$ & $\begin{array}{l}\text { Formação continuada em História, voltada à } \\
\text { implementação da Lei } 10.639 / 2003\end{array}$ \\
\hline $\begin{array}{l}\text { A Lei } 10.639 \text { e o ensino de Inglês em uma escola } \\
\text { pública }\end{array}$ & $\begin{array}{l}\text { Possibilidades de trabalho das questões étnico- } \\
\text { raciais nas aulas de Inglês }\end{array}$ \\
\hline $\begin{array}{l}\text { A Lei 10639/2003 e a literatura luso-africana e } \\
\text { afro-brasileira na escola }\end{array}$ & $\begin{array}{l}\text { Repercussão das determinações da lei nos livros } \\
\text { didáticos }\end{array}$ \\
\hline $\begin{array}{l}\text { Arcabouço jurídico normativo pedagógico da Lei } \\
\text { federal 10.639/2003 na Universidade Federal de } \\
\text { Uberlândia: avanços e limites }\end{array}$ & $\begin{array}{l}\text { Políticas e ações para implementação da lei na } \\
\text { Universidade }\end{array}$ \\
\hline $\begin{array}{l}\text { Movimento artístico e educacional de fundamento } \\
\text { negro na Praça da República: São Paulo 1960-1980 }\end{array}$ & Arte afrodescendente \\
\hline $\begin{array}{l}\text { A educação para as relações étnico-raciais e o } \\
\text { estudo de História e Cultura da África e afro- } \\
\text { brasileira: formação, saberes e práticas educativas }\end{array}$ & Formação continuada de professores \\
\hline $\begin{array}{l}\text { A criança negra na literatura infantil brasileira } \\
\text { contemporânea }\end{array}$ & Caracterização da criança negra em livros infantis \\
\hline Escola e questão racial: a avaliação dos estudantes & $\begin{array}{l}\text { Avaliação dos estudantes negros sobre trabalho com } \\
\text { questões raciais }\end{array}$ \\
\hline $\begin{array}{l}\text { Entre leões, coelhos, tranças e guerras: dilemas } \\
\text { contemporâneos na literatura infantil angolana de } \\
\text { Ondjaki }\end{array}$ & $\begin{array}{l}\text { Diálogo da literatura infantil angolana com cultura } \\
\text { brasileira }\end{array}$ \\
\hline $\begin{array}{l}\text { A influência dos Fóruns de Educação e Diversidade } \\
\text { Étnico-racial na implementação da política de } \\
\text { promoção da igualdade racial }\end{array}$ & $\begin{array}{l}\text { Participação dos movimentos sociais na } \\
\text { implementação da lei }\end{array}$ \\
\hline
\end{tabular}

A maioria dos trabalhos aborda a formação de professores: sete apontam a necessidade de investimento em formação inicial e continuada de professores; três problematizam a efetividade da formação continuada; dois evidenciam a necessidade de maior participação das universidades na implementação da lei; e dois deles enfatizam a importância da responsabilização dos órgãos públicos educacionais e da desvinculação entre as políticas públicas e uma determinada gestão política; quatro indicam que a lei somente é posta em ação por iniciativas pessoais; dois identificam a participação ativa de 


\section{pro.posıções}

eISSN 1980-6248

professores na execução das políticas púbicas; três apontam a ausência de discussão sistemática dos conteúdos da lei e dois mostram a distância entre discurso e práticas cotidianas; cinco deles concluem que há resistência de professores e gestores na aplicação da lei.

Das pesquisas sobre livros didáticos e outros recursos de ensino, quatro reiteram a interpretação de que os livros reproduzem estereótipos e visões negativas em relação à população negra; oito revelam bons resultados no uso de recursos didáticos como jogos, livros infantis, manifestações culturais populares e recursos da Internet; e uma aponta o aumento e a melhoria nas produções que representam o negro, após a promulgação da Lei.

Dois estudos reforçam que a lei questiona a forma como o currículo é estruturado e vivenciado, e um deles reflete sobre a relatividade da ação da implantação da legislação nas escolas em relação à sua capacidade de minimizar problemas sociais historicamente produzidos. Nesse sentido, uma produção demonstra a persistência do mito de igualdade racial na escola e uma outra aponta a complexidade da cultura africana. Um trabalho aborda as deficiências dos espaços participativos.

Ao debruçarem-se sobre as relações escolares, uma pesquisa conclui pela necessidade de autonomia do professor no planejamento pedagógico e quatro demonstram a necessidade de maior visibilidade do legado afrodescendente nas escolas.

Muitas pesquisas vêm, portanto, tentando compreender de que maneira as ações de formação de professores e elaboração de material têm levado a resultados mais favoráveis ao objetivo de vivência dos preceitos legais no cotidiano das escolas. Algumas têm trazido à tona a constatação de que, mesmo com a oferta de formação e com a produção e a disponibilização de materiais didáticos, ainda há, por parte de professores, gestores de unidades e sistemas de ensino, resistência à lei e falta de interesse por ela. 


\section{pro.posıções}

\section{Considerações finais}

O exercício de levantamento dessas políticas e pesquisas nos permitiu combater a “falsa impressão de que as Políticas Públicas são coerentes entre si, organizadas" (Secchi, 2012, p.13) e compreender que "a formulação e implementação de políticas sociais e educacionais advindas do Estado tomam a forma e a expressão das relações e das forças sociais em disputa" (Deitos, 2010, p.12).

Nesse sentido, a coesão entre políticas públicas relacionadas à Lei 10.639/03 e entre elas e as demais políticas educacionais é aqui assinalada como fator importante para a possibilidade de sua implementação. Inúmeros problemas nesse processo relacionam-se às deficiências no estabelecimento de vínculos entre políticas. "As acções que garantem o funcionamento do sistema educativo são determinadas por um feixe de dispositivos reguladores que muitas vezes se anulam entre si, ou pelo menos, relativizam a relação causal entre princípios, objetivos, processos e resultados" (Barroso, 2005, p. 2).

Uma das articulações que demonstra ser deficiente, nesse ponto, é aquela que acontece entre as políticas do Ensino Superior e as da Educação Básica: o tema mais problematizado no levantamento de produções acadêmicas a respeito da Lei 10.639 foi o da formação inicial e continuada de professores: alguns trabalhos pontuam a necessidade de maior participação das universidades nesse aspecto e também na produção e na divulgação de conhecimentos pertinentes aos conteúdos incluídos pela lei no currículo escolar.

Outra política na qual observamos uma disparidade em relação à implementação da Lei 10.639/03 é a dos livros didáticos. Nas pesquisas levantadas, ainda predomina a constatação de que os livros utilizados nas escolas reiteram visões negativas sobre o negro, em detrimento das que apontam um incremento nesses materiais após a promulgação da Lei 10.639/03.

Uma das produções acadêmicas revela, ainda, desarticulação entre as políticas relacionadas à Lei 10.639/03 e as propostas de formação continuada na área de História. Os elementos apontados como principais responsáveis por essa disparidade são as dificuldades que podem ser enfrentadas em muitas iniciativas de formação docente. 


\section{pro.posıções}

eISSN 1980-6248

Um dos estudos constata, ainda, que o professorado necessita de maior autonomia na construção do seu trabalho para a melhoria da qualidade do ensino-aprendizagem, demonstrando uma possível incongruência entre gestões escolares e premissas de políticas públicas, como aquelas relativas à implementação da Lei 10.639/03.

As ações voltadas à participação popular na agenda das políticas públicas, analisadas a partir do levantamento abordado no Eixo 4, também demonstram deficiências e limites no padrão representativo adotado - que se pauta em um modelo democrático e participativo de gestão e que, aparentemente, engloba de forma ampla tanto os múltiplos atores quanto a diversidade de experiências do território nacional -, quando confrontado com os resultados de diversas produções bibliográficas que consideram que o conteúdo dessa legislação não chega à escola, exceto em algumas experiências isoladas; que não há discussão sistemática de seus conteúdos na escola; e que existe uma distância entre o discurso e a prática dos profissionais da Educação em relação à Lei 10.639/03.

Os pontos fracos dessas políticas são os mesmos encontrados em outras práticas de gestão participativa, sobretudo as dificuldades de mobilização e de presença dos públicos envolvidos e o engessamento na tomada de decisões, subordinadas a processos políticos e burocráticos, dificultando e atrasando ações e gerando desânimo dos participantes e descrença na efetividade dos mecanismos participativos (Tatagiba \& Teixeira, 2006).

Uma das dissertações elencadas em nosso levantamento, por exemplo, aponta, em suas conclusões:

Os Fóruns padecem com a falta de articulação interna, com a dificuldade de diálogo com o poder local e com a falta de apoio para a realização das ações. Outros entraves para a potencialização do funcionamento dos Fóruns residem na dificuldade da Secadi no acompanhamento de suas ações. (Rosa, 2013)

Por fim, sinalizamos a problemática de vinculação de recursos para execução das políticas públicas. A incorporação, em 2015, da Secretaria de Políticas da Promoção da Igualdade Racial a outras duas Secretarias e ao Ministério da Cidadania, por exemplo, representa um retrocesso não só para a visibilidade das questões raciais, mas também para o investimento público em ações de promoção de igualdade racial. Nesse ínterim, também se constata a descontinuidade das políticas de governo em detrimento das políticas de 


\section{pro.posıções}

eISSN 1980-6248

Estado, o que nos leva à reflexão a respeito das dificuldades estruturais da organização político-econômica brasileira, refletidas na implementação da Lei 10.639/03.

Entre os problemas que surgem no processo de implementação desta lei há, sem dúvida, especificidades relacionadas ao seu próprio conteúdo, que, por estabelecer ideais de igualdade racial e respeito às diferenças, é conflitante com uma realidade social - sobre a qual a escola exerce influência e pela qual é, por sua vez, influenciada - que ainda se estrutura e organiza com base em preconceitos raciais e sociais naturalizados.

Esses preconceitos ficam explícitos no ambiente escolar, tanto pelo currículo oficial quanto por aquilo que se convencionou chamar de currículo oculto: conteúdos implícitos em valores e atitudes que perpassam as relações escolares de forma a estimular e promover a reprodução desses mesmos valores e atitudes.

O currículo oculto é constituído por todos aqueles aspectos do ambiente escolar que, sem fazer parte do currículo oficial, explícito, contribuem, de forma implícita para aprendizagens sociais relevantes ... o que se aprende no currículo oculto são fundamentalmente atitudes, comportamentos, valores e orientações. (Silva, 2003)

Tendo em vista que a própria história da escola faz parte do desenvolvimento do aparato institucional voltado à manutenção das relações de poder e controle social e racial, a dificuldade na implementação da Lei 10.639/2003, bem como de outras legislações que se propõem a promover alterações no relacionamento com o saber e com as mudanças estruturais no uso de tais saberes para a transformação social, reside na própria configuração do Estado. O racismo institucional configura-se, portanto, como empecilho estrutural para a implementação da Lei 10.639/03.

Assim, é possível assinalar que os diversos problemas presentes no processo de implementação da legislação aqui estudada, e que são comuns a outras políticas educacionais, são transpassados pelos comportamentos discriminatórios cotidianos nas instituições educacionais de todos os níveis - práticas de difícil identificação e combate, pois são intrínsecas às relações institucionais.

O racismo institucional não se expressa em atos manifestos, mas atua de forma difusa no funcionamento cotidiano de instituições e organizações, que operam de forma diferenciada, do ponto de vista racial, na distribuição de serviços, bens e oportunidades aos diferentes segmentos da população. (Silva, 2003, p.6) 


\section{pro.posıções}

eISSN 1980-6248

Algumas evidências dessa constatação foram encontradas nos levantamentos de produções bibliográficas e de políticas públicas.

" $\mathrm{Na}$ ausência da adesão massiva das pessoas da escola a uma política de educação visionária e audaciosa, a mudança social adquire, antes de tudo, aparências de uma imposição a ser ignorada pelo maior tempo possível", afirma Perrenoud (1999). O desinteresse e a resistência dos profissionais de Educação à integração das temáticas raciais na escola são o fator que mais claramente evidencia a presença do racismo institucional. A ineficiência de alguns programas de formação docente continuada pode corroborar essa constatação, bem como os apontamentos relativos à ausência de espaços formais para discussão dos conteúdos da lei nas escolas, à execução da Lei 10.639/03 apenas a partir de iniciativas pessoais de professores interessados, à persistência de conteúdos discriminatórios nos livros didáticos e à invisibilidade da cultura afrodescendente nas escolas.

Assinalamos, ainda, que as políticas relacionadas à formação dos profissionais de ensino apresentam deficiências no aspecto do compartilhamento do saber. Essa postura contribui para dissociar teoria e prática, enxergar os cursos como intervenções pontuais alheias ao processo de formação integral do profissional, que se dá na práxis cotidiana, podendo prejudicar sua efetividade na expansão do domínio dos conteúdos entre as comunidades escolares, esvaziando-os: “A idéia é de que não se trata de conhecer por conhecer, mas de ligar o conhecimento científico a uma cognição prática, isto é, de compreender a realidade para transformá-la” (Libâneo, 2011, p.57).

Há ainda, nesse quadro, o questionamento de dois estudos a respeito da forma como o currículo é estruturado, e de um outro estudo a respeito das limitações de atuação da escola em relação a problemas historicamente produzidos, que nos levam a refletir sobre a presença de ideias racistas em tais estruturas educacionais.

Novamente, é necessário sinalizar as deficiências nos mecanismos de gestão participativa em processos relacionados à Lei 10.639/03, apontando-as como parte de um arcabouço institucional que contraria os princípios mais intrínsecos dessa legislação, ao servir como mantenedor das estruturas de poder:

As preocupações assinaladas pelas autoridades educacionais em relação à existência de uma burocracia que tudo emperra e dificulta, zelosa dos poderes que amealhou ao longo do 


\section{pro.posıções}

e-ISSN 1980-6248

tempo, deles não aceitando se apartar, retratam não a burocracia propriamente dita, mas uma camada estamental de domínio alheia ao povo, arraia-miúda cuja participação no jogo político e administrativo é acidental ou suplementar, nunca determinante, pois esse é o papel reservado à comunidade restrita e condutora. (Perrenoud, 1999, p. 45)

Também é importante apontar que as pesquisas levantadas englobam toda a Educação Básica, passando pela Educação de Jovens e Adultos, a Educação não formal, a educação quilombola. Abarcam inúmeras áreas de saber e abordam também a interdisciplinaridade. Essa abrangência pode ser um indicador da relação determinante do racismo institucional com os problemas enfrentados na execução da Lei 10.639/03, visto que as dificuldades aparecem em todo o sistema de ensino brasileiro, não são pontuais ou locais (embora haja características mais específicas dessas dificuldades que são gestadas por meio de aspectos particulares de cada escola e/ou localidade).

É importante ressaltar que a Lei 10.639/03 altera a Lei de Diretrizes e Bases da Educação Nacional, o mais importante marco regulatório contemporâneo da Educação no Brasil. Conforme constatado no Eixo 1, as próprias regulamentações da Lei 10.639/03 a apresentam como meio para reparar uma dívida social brasileira em relação à população negra - contraída desde a escravidão prolongada, passando pelo formato de sua abolição, culminando nas políticas de embranquecimento, no mito da democracia racial e em inumeráveis formas de discriminação no cotidiano. Ainda assim, persiste a dificuldade do cumprimento de seus preceitos.

Os documentos que regulamentam a Lei 10.639/03 possuem embasamento teórico e legal de qualidade e abrangente para que ações para sua implementação fossem iniciadas e gerenciadas. Parte deles foi disponibilizada para redes de ensino e escolas e se encontra acessível pela Internet. Questionamos se seus conteúdos, apesar disso, são conhecidos pelos profissionais da Educação, se têm sido contemplados por projetos pedagógicos e práticas de ensino, e de que forma os órgãos por elas responsáveis se mobilizam para realizar o acompanhamento de seus impactos nas redes e unidades de ensino.

Podemos considerar que o período de uma década de existência dessa Lei seja curto do ponto de vista histórico, diante do longo período de discriminação e racismo oficiais no Brasil, que ainda permeiam nossa mentalidade, nossas práticas sociais e institucionais e diante dos tempos e dos espaços demandados para a tomada de decisões coletivas. 


\section{pro-posıções

Constatadas essas limitações na atuação do sistema educacional para a implementação da Lei 10.639/03, por inserir-se em um aparato institucional que se choca com seu ideário, julgamos oportuno ressaltar que a atuação do Movimento Negro tem papel relevante nessa articulação, incluindo a sua representatividade nos espaços institucionais estatais, mas não se limitando a ela.

A pesquisa relacionada à implementação da Lei 10.639/03 revelou uma grande diversidade de temáticas que necessitam ser aprofundadas, para a melhor compreensão de seus múltiplos aspectos e a elaboração de alternativas de ação e intervenção.

Concluímos estas considerações, apontando nossa crença na possibilidade de tensionamento das relações escolares e políticas para ampliação do espaço ocupado pelas questões relacionadas à Lei 10.639/2003 nos espaços institucionais, o que só pode ser feito quando evidenciadas as práticas que negam ou cerceiam esse espaço. Consideramos que essa tarefa, coletiva e processual, pode se configurar em uma contribuição para a desconstrução do ideário e das práticas que mantêm vivo e operante o racismo institucional. E que cabe à universidade e à pesquisa um papel importante nesse processo. 


\section{pro.posıções}

eISSN 1980-6248

\section{Referências Bibliográficas}

Barroso, J. (2005, outubro). O Estado, a educação e a regulação das políticas públicas. Educação e Sociedade, 92, 725-751.

Cerri, L.F. (2006). Usos públicos da história no Brasil contemporâneo: demandas sociais e políticas de Estado. Araucaria. Revista Iberoamericana de Filosofía, Política y Humanidades, 15, 3-19.

Cury, C. R. J. (2000). A educação como desafio na ordem jurídica. In E. M. T. Lopes, L. M. de F. Filho, \& C. G. Veiga (Eds.), 500 anos de educação no Brasil. Belo Horizonte, MG: Autêntica.

Deitos, R. A. (2010). Políticas públicas e educação: aspectos teórico-ideológicos e socioeconômicos. Acta Scientiarum, 2, 209-218.

Fernandes, J. R. O. (2005, setembro/dezembro). Ensino de história e diversidade cultural: desafios e possibilidades. Cadernos Cedes, 67, 378-388.

Figueira, V. M. (1999). O preconceito racial na escola. In E. L. Nascimento (Org.), O preconceito racial na escola. Brasília, DF: Senado Federal.

Gadotti, M. (2008). História das idéias pedagógicas. São Paulo, SP: Ática.

Gentili, P. (2009, setembro/dezembro). O direito à educação e as dinâmicas de exclusão na América Latina. Educação e Sociedade, 109, 1059-1079.

Gomes, J. B. B. (2001). Ação afirmativa e princípio constitucional da igualdade: o direito como instrumento de transformação social. Rio de Janeiro, RJ: Renovar.

Libâneo, J. C. (2011). A escolarização e o novo paradigma produtivo. In J. C. Libâneo, Adeus professor, adeus professora? Novas exigências educacionais e profissão docente (pp. 441461). São Paulo/SP: Cortez.

Morin, E. (2005). Os sete saberes necessários à educação do futuro. São Paulo/SP: Cortez.

Perrenoud, P. (1999, setembro/dezembro). Formar professores em contextos sociais em mudança. Prática reflexiva e participação crítica. Revista Brasileira de Educação, 12, 521. 


\section{pro.posições}

eISSN 1980-6248

Prado, E. M., \& Graf, M. E. de C. (2010, setembro). O ensino da história da África nas escolas brasileiras. Anais do $7^{\circ}$ Congresso Ibérico de Estudos Africanos (pp. 35-40). Lisboa: CEA-IUL;CEI.

Rosa, B. da S. (2013). A influência dos fóruns de educação e diversidade étnico-racial na implementação da política de promoção da igualdade racial. Dissertação de Mestrado em Administração Pública, Faculdade de Economia, Administração, Contabilidade e Ciência da Informação e Documentação, Universidade de Brasília, Brasília.

Sanchez, L. P. (2014). O ENEM como ferramenta da implementação da Lei 10.639/2003 competências e habilidades para a transformação social? Dissertação de Mestrado em Mudança Social e Participação Política, Escola de Artes, Ciências e Humanidades, Universidade de São Paulo, São Paulo.

Santos, A. de F. T. (2001). Cultura e educação a serviço da transformação social. In A. M. Magaldi, C. Alves, \& J. G. Gondra (Orgs.), Educaşão no Brasil: história, cultura e politica. Bragança Paulista, SP: EDUSF.

Santos, S. Q. S., \& Machado, V. L. de C. (2005, janeiro/março). Políticas públicas educacionais: antigas reivindicações, conquistas (Lei 10.639) e novos desafios. Ensaio: Avaliação de Política Públicas Educacionais, 58, 95-112.

Secchi, L. (2012). Políticas públicas: conceitos, esquemas de análise, casos práticos. São Paulo, SP: Cengage Learning.

Silva, G. da, \& Araújo, M. (2005). Da interdição escolar às ações educacionais de sucesso: escolas dos movimentos negros e escolas profissionais, técnicas e tecnológicas. In J. Romão (Org.), História da educação dos negros e outras histórias (pp. 64-82). Brasília, DF: Ministério da Educação. Secretaria de Educação Continuada, Alfabetização e Diversidade.

Silva, P. B. G. (2007, setembro/dezembro). Aprender, ensinar e relações étnico-raciais no Brasil. Educação, 3(63), 486-506.

Silva, T. T. da. (2003). Quem escondeu o currículo oculto? In T. T. da SILVA, Documentos de identidades: uma introducão às teorias de currículo (pp. 80-92). Belo Horizonte/MG: Autêntica. 


\section{pro.posıções \\ eISSN 1980-6248}

$10.1590 / 1980-6248-2015-0141$

Siss, A. (2003). Afro-brasileiros, cotas e ação afirmativa: rã̃ôes históricas. Rio de Janeiro, RJ: Quartet.

Tatagiba, L., \& Teixeira, A. C. X. (2006, janeiro/junho). Participação e democracia: velhos e novos desafios. Civitas, 1, 223-240.

Submetido à avaliação em 11 de fevereiro de 2016; aceito para publicação em 11 de abril de 2016. 